\title{
A ressignificação na prática de avaliar do professor alfabetizador pautada nos direitos de aprendizagem
}

\author{
Adelma das Neves Nunes Barros-Mendes \\ Adriana Carvalho Souza Castro \\ Heloane Baia Nogueira \\ Rosivaldo Gomes
}

\section{Resumo}

Este texto apresenta reflexões acerca do processo de ressignificação de práticas pedagógicas dos professores participantes do Pacto Nacional pela Alfabetização na Idade Certa (Pnaic), na Universidade Federal do Amapá (Unifap). Com base na abordagem qualitativa de pesquisa em educação, realizou-se um mapeamento fundamentado no paradigma indiciário, tendo por foco indícios em dados documentais de instrumentos formativos construídos na formação: o diário reflexivo e o relatório descritivo. A análise demonstrou que, sob dois aspectos - incorporação no fazer docente de um planejamento de ações/práticas didáticas alinhadas aos direitos de aprendizagem e de uma avaliação formativa alicerçada nos direitos de aprendizagem -, os alfabetizadores, então apoiados na dimensão de avaliação classificatória, passaram, no decorrer da formação continuada, a fundar-se em outra, diagnóstica, emancipatória, formativa/formativa-reguladora.

Palavras-chave: direitos de aprendizagem; prática pedagógica; Pacto Nacional pela Alfabetização na Idade Certa. 


\section{Abstract \\ Reframing of the literacy teacher's evaluation practices grounded in the learning rights}

This text reflects on the process of reframing pedagogical practices of teachers taking part at the National Agreement for Literacy at the Right Age (PNAIC) at the Federal University of Amapá (UNIFAP). From a qualitative approach to research in education, a mapping anchored in the indicative paradigm was carried out, focusing on evidence in documentary data from formative instruments developed in training: the reflective journal and the descriptive report. The analysis showed that under two aspects - the incorporation into teaching of didactic practices/actions aligned with the learning rights and the incorporation into teaching of a formative assessment based on learning rights -, literacy teachers, then based on the dimension of classificatory assessment, during the course of continuing education, started to be based on another, diagnostic, emancipatory, formative / formative-regulatory.

Keywords: learning rights; didactic practices; National Agreement for Literacy at the Right Age.

\section{Resumen \\ La resignificación en la práctica de evaluar del profesor alfabetizador con base en los derechos de aprendizaje}

Este texto presenta reflexiones sobre el proceso de reencuadre de las prácticas pedagógicas de los profesores que participan en el Pacto Nacional por la Alfabetización en la Edad Correcta (Pacto Nacional pela Alfabetização na Idade Certa - Pnaic), en la Universidade Federal do Amapá (Unifap). Con base en el abordaje cualitativo de investigación en educación, se realizó un mapeo basado en el paradigma evidencial, enfocándose en la evidencia en datos documentales de instrumentos formativos construidos en la formación: el diario reflexivo y el informe descriptivo. El análisis mostró que, bajo dos aspectos -incorporación en el hacer docente de una planificación de acciones/prácticas didácticas alineadas con los derechos de aprendizaje y de una evaluación formativa basada en los derechos de aprendizaje-, los alfabetizadores, basados en la dimensión de evaluación clasificatoria, pasaron, en el curso de la formación continua, a basarse en otra, diagnóstica, emancipadora, formativa/ formativa-reguladora.

Palabras clave: derechos de aprendizaje; práctica pedagógica; Pacto Nacional por la Alfabetización en la Edad Correcta. 


\section{Introdução}

A avaliação, principalmente no campo da alfabetização, desde a década de 1980, configurou-se como objeto de debates sociais em diversos meios de comunicação e publicações de pesquisa no contexto brasileiro. Além disso, tem ocupado lugar privilegiado nas discussões educacionais e preocupações dos professores, já que apresenta estreita relação com o currículo escolar, com o planejamento didático e com o processo de ensino e aprendizagem dos saberes ensinados na escola (Brasil. MEC. SEB, 2012d).

No Pacto Nacional pela Alfabetização na Idade Certa (Pnaic), a avaliação ocupou espaço de destaque, em virtude de o programa ter entre seus princípios a avaliação em uma perspectiva diagnóstica, favorecendo a organização de instrumentos de monitoramento das aprendizagens baseadas nos direitos de aprendizagem. Assim, para uma ação didática consistente, há de se construir uma atividade diagnóstica que permita ao professor ter conhecimento sobre os alunos, com base no qual possa (re)organizar seu planejamento em função das necessidades reais destes e em função dos objetivos de aprendizagens, devidamente bem definidos (Brasil. MEC, SEB, 2012a).

Este texto resulta da análise de um conjunto de documentos elaborados ao longo da formação continuada (FC) de alfabetizadores no programa Pnaic, na Universidade Federal do Amapá (Unifap). Trata-se de dados de ações já realizadas e a motivação para as reflexões nasceu de indícios percebidos no decorrer dos encontros da FC e em seus registros. Partiu-se da hipótese que as mudanças introduzidas pelos alfabetizadores em suas ações/práticas pedagógicas estão alicerçadas nos direitos de aprendizagem, uma vez que estes possibilitam "planejar e orientar os avanços do ensino e das aprendizagens no ciclo de três anos de alfabetização com intencionalidade didática e pedagógica" (Brasil. MEC. SEB, 2012b, p. 44).

Optou-se pela abordagem qualitativa de pesquisa em educação (Lüdke; André, 1986; André, 2005) e realizou-se um mapeamento ancorado no paradigma indiciário (Ginzburg, 1991), que auxiliou a captação de indícios nos dados revelados pelos instrumentos formativos, explicitados mais adiante, denominados diários reflexivos (DR), momento interdisciplinar (MI), relatórios descritivos de formação (RDF). Os indícios também foram inventariados no diagnóstico realizado com os alfabetizadores no início da FC acerca das práticas pedagógicas de alfabetização, incluindo o modo como eles avaliavam os conhecimentos no processo de ensino das crianças.

Para estabelecer as discussões, considerou-se a abordagem enunciativodiscursiva bakhtiniana "que tem a vantagem de valorizar o corpus e despertar no analista a capacidade de dialogar com esse corpus e, a partir de sua materialidade, de suas particularidades, surpreender nas incontáveis formas assumidas pela língua [...]" (Brait, 2001, p. 16).

O texto organizou-se nos seguintes momentos: discutem-se algumas definições de avaliação; descreve-se brevemente o aporte metodológico; explicita-se a organização dos dados; segue-se com a descrição e discussão dos achados; por fim, é tecida breve consideração final. 


\section{Implementação do Pnaic}

O Programa Pacto Nacional pela Alfabetização na Idade Certa (Pnaic) foi instituído pelo Ministério da Educação, por meio da Portaria no 867, de 4 de julho de 2012, que, no Artigo 5, esclarece os objetivos das ações do pacto:

I. garantir que todos os estudantes dos sistemas públicos de ensino estejam alfabetizados, em Língua Portuguesa e em Matemática, até o final do $3^{\circ}$ ano do ensino fundamental;

II. reduzir a distorção idade-série na Educação Básica;

III. melhorar o Índice de Desenvolvimento da Educação Básica (Ideb);

IV. contribuir para o aperfeiçoamento da formação dos professores alfabetizadores;

V. construir propostas para a definição dos direitos de aprendizagem e desenvolvimento das crianças nos três primeiros anos do ensino fundamental. (Brasil. MEC, 2012).

No Pnaic, os entes governamentais (Governo Federal, Distrito Federal, estados e municípios) comprometem-se legalmente a:

- alfabetizar todas as crianças em língua portuguesa e em matemática;

- realizar avaliações anuais universais, aplicadas pelo Inep, junto aos concluintes do $3^{\circ}$ ano do ensino fundamental;

- no caso dos estados, apoiar os municípios que tenham aderido às Ações do Pacto, para sua efetiva implementação (Brasil. MEC, 2012)

Dessa maneira, o Pnaic está embasado em eixos de atuação. O principal deles é a formação continuada de professores alfabetizadores e orientadores de estudo. Essas ações são complementadas por outros três eixos de atuação: i) materiais didáticos, obras literárias, obras de apoio pedagógico, jogos e tecnologias educacionais; ii) avaliações sistemáticas; iii) gestão, mobilização e controle social. O programa está organizado por rede de formação, envolvendo universidades, secretarias de educação e escolas públicas dos sistemas de ensino. A formação continuada começa nas universidades públicas que compõem a rede.

\section{Avaliação: perspectivas panorâmicas e conceituais no campo da alfabetização}

Na literatura sobre a avaliação é possível verificar, conforme Ferreira e Leal (2010), pelo menos três paradigmas para avaliar a aprendizagem:

1) paradigma ritualístico, que se realizava em eventos públicos, práticas avaliativas de rituais solenes para demonstração dos conhecimentos acumulados; 
2) paradigma positivista/tradicional, no qual os saberes e a avaliação são tratados de forma objetiva e medem os resultados finais de aprendizagem;

3) paradigma interacional, segundo o qual a aprendizagem é construída na interação com o outro, e em processo mútuo e contínuo (Luckesi, 2000).

Neles, pode-se dizer, tal como defendido por Ferreira e Leal (2010) e Suassuna (2007), há quatro grandes modos de configuração da avaliação educacional da aprendizagem: classificatória/tradicional ou somativa, diagnóstica, emancipatória, formativa/formativa-reguladora.

Sustentada pelo paradigma tradicional, a avaliação classificatória focaliza a capacidade de reprodução de determinado conteúdo repassado pelo professor, configurando-se em um viés mimético, conforme Suassuna (2007). De caráter quantitativo e somativo, esse viés está fundamentado no paradigma positivista e é realizado, nas práticas do letramento escolar, na maioria das vezes, ao término de um período determinado de aprendizagem, objetivando apenas a aferição de notas e tendo como finalidade, conforme salienta Luckesi (2000), estabelecer um caráter classificatório e seletivo de alunos e de suas aprendizagens.

Já a avaliação diagnóstica pode indicar os níveis consolidados pelo aluno, bem como suas dificuldades ao longo do processo de aprendizagem na alfabetização e também possibilita que o professor possa planejar estratégias de intervenção necessárias a seus avanços. A avaliação emancipatória se caracteriza como processo que envolve tanto a análise quanto a descrição de uma dada realidade educacional e está "situada numa vertente político-pedagógica cujo interesse primordial é emancipador, ou seja, libertador, visando provocar a crítica, de modo a libertar o sujeito de condicionamentos deterministas" (Saul, 1995, p. 61).

Sobre a avaliação formativa, Ferreira e Leal (2010) destacam que o ato avaliativo deve ser pensado como uma estratégia para regular e adaptar a prática pedagógica às necessidades dos alunos, mais do que propriamente medir os seus resultados finais. Assim, poderá servir de guia para que o professor possa repensar a avaliação e estratégias didáticas, pois "avaliamos em diferentes momentos, com diferentes finalidades" (Ferreira; Leal, 2010, p. 30).

Nessa perspectiva de avaliação em que a FC do Pnaic se fundamenta, os quadros de direitos de aprendizagem serviram de alicerce não somente para que os professores compreendessem que há aspectos diversos que integram desde o processo de avaliar até o de planejamento das ações didáticas, mas, para o alfabetizador, organizam as capacidades e os conhecimentos que as crianças têm direito de aprender em cada ano (Brasil. MEC. SEB, 2012a).

A título de exemplo, o Quadro 1 apresenta o recorte de um eixo desses quadros de direitos de aprendizagem. 


\section{Quadro 1 - Direitos de aprendizagem referentes ao eixo de análise linguística}

\begin{tabular}{|c|c|c|c|}
\hline $\begin{array}{l}\text { Análise linguística: } \\
\text { apropriação do Sistema de Escrita Alfabética }\end{array}$ & Ano 1 & Ano 2 & Ano 3 \\
\hline Escrever o próprio nome. & I/A/C & & \\
\hline Reconhecer e nomear as letras do alfabeto. & $\mathrm{I} / \mathrm{A} / \mathrm{C}$ & & \\
\hline Diferenciar letras de números e outros símbolos. & I/A/C & & \\
\hline $\begin{array}{l}\text { Conhecer a ordem alfabética e seus usos em diferentes } \\
\text { gêneros. }\end{array}$ & $\mathrm{I} / \mathrm{A} / \mathrm{C}$ & & \\
\hline $\begin{array}{l}\text { Reconhecer diferentes tipos de letras em textos } \\
\text { diferentes gêneros e suportes textuais. }\end{array}$ & I/A & $\mathrm{A} / \mathrm{C}$ & \\
\hline $\begin{array}{l}\text { Usar diferentes tipos de letras em situações de escrita de } \\
\text { palavras e textos. }\end{array}$ & I & $\mathrm{A} / \mathrm{C}$ & $\mathrm{C}$ \\
\hline $\begin{array}{l}\text { Compreender que palavras diferentes compartilham certas } \\
\text { letras. }\end{array}$ & $\mathrm{I} / \mathrm{A} / \mathrm{C}$ & & \\
\hline $\begin{array}{l}\text { Perceber que palavras diferentes variam quanto ao número, } \\
\text { repertório e ordem deletras. }\end{array}$ & $\mathrm{I} / \mathrm{A} / \mathrm{C}$ & & \\
\hline $\begin{array}{l}\text { Segmentar oralmente as sílabas de palavras e comparar } \\
\text { as palavras quanto ao tamanho. }\end{array}$ & $\mathrm{I} / \mathrm{A} / \mathrm{C}$ & & \\
\hline Identificar semelhanças sonoras em sílabas e em rimas. & $\mathrm{I} / \mathrm{A} / \mathrm{C}$ & & \\
\hline $\begin{array}{l}\text { Reconhecer que as sílabas variam quanto às suas } \\
\text { composições. }\end{array}$ & $\mathrm{I} / \mathrm{A} / \mathrm{C}$ & & \\
\hline Perceber que as vogais estão presentes em todas as sílabas. & $\mathrm{I} / \mathrm{A} / \mathrm{C}$ & & \\
\hline Ler, ajustando a pauta sonora ao escrito. & I/A/C & & \\
\hline $\begin{array}{l}\text { Dominar as correspondências entre letras ou grupos de } \\
\text { letras e seu valor sonoro, de modo a ler palavras e textos. }\end{array}$ & I/A & $\mathrm{A} / \mathrm{C}$ & $\mathrm{C}$ \\
\hline $\begin{array}{l}\text { Dominar as correspondências entre letras ou grupos de letras } \\
\text { e seu valor sonoro, de modo a escrever palavras e textos. }\end{array}$ & $\mathrm{I} / \mathrm{A}$ & $\mathrm{A} / \mathrm{C}$ & $\mathrm{C}$ \\
\hline
\end{tabular}

[ I ] Introduzir; [ A ] Aprofundar; [ C ] Consolidar.

Fonte: Brasil. MEC. SEB (2012c, p. 37).

Como se vê, a progressão do processo de aprendizagem pode ser acompanhada pelo professor com a definição mais clara do que deverá introduzir (I), aprofundar (A) e consolidar (C), sendo necessário que os direitos de aprendizagem sejam trabalhados com os alunos. Verifica-se, por exemplo, que é possível determinado conhecimento ser introduzido em um ano e aprofundado em anos posteriores. Para auxiliar no processo de avaliação dos alunos em uma perspectiva formativa, na FC, foram oferecidos ao professor os modelos de fichas mostradas nos Quadros 2 e 3. Assim, essas formas de monitoramento das aprendizagens possibilitam ao docente direcionar seu planejamento, desenvolvendo estratégias para alcançar as metas de aprendizagens e de ensino.

A visão formativa de avaliação defendida pelo Pnaic aproxima Ferreira e Leal (2010), Suassuna (2007) e Perrenoud (1999), pois, para esses autores, o real objetivo de uma avaliação formativa é favorecer, por meio de diferentes estratégias, oportunidades de aprendizagem, considerando as particularidades dos alunos, seus limites, possibilidades e potencialidades de avanços nas aprendizagens dos saberes. 
Quadro 2 - Ficha sugerida pelo Pnaic e utilizada como instrumento de registro
das avaliações feitas sobre as aprendizagens individuais das crianças

\begin{tabular}{|c|c|c|c|c|}
\hline $\begin{array}{l}\text { Análise linguística: } \\
\text { apropriação do Sistema de Escrita Alfabética }\end{array}$ & Fev. & Jun. & Ago. & Dez. \\
\hline \multicolumn{5}{|l|}{ Escreve o próprio nome. } \\
\hline \multicolumn{5}{|l|}{ Reconhece e nomeia as letras do alfabeto. } \\
\hline \multicolumn{5}{|l|}{ Diferencia letras de números e outros símbolos. } \\
\hline \multicolumn{5}{|l|}{$\begin{array}{l}\text { Conhece a ordem alfabética e seus usos em diferentes } \\
\text { gêneros. }\end{array}$} \\
\hline \multicolumn{5}{|l|}{$\begin{array}{l}\text { Reconhece diferentes tipos de letras em textos de diferentes } \\
\text { gêneros e suportes textuais. }\end{array}$} \\
\hline \multicolumn{5}{|l|}{ Compreende que palavras diferentes compartilham certas letras. } \\
\hline \multicolumn{5}{|l|}{$\begin{array}{l}\text { Percebe que palavras diferentes variam quanto ao número, } \\
\text { repertório e ordem de letras. }\end{array}$} \\
\hline \multicolumn{5}{|l|}{$\begin{array}{l}\text { Segmenta oralmente as sílabas de palavras e compara as } \\
\text { palavras quanto ao tamanho. }\end{array}$} \\
\hline \multicolumn{5}{|l|}{ Identifica semelhanças sonoras em sílabas e em rimas. } \\
\hline \multicolumn{5}{|l|}{ Reconhece que as sílabas variam quanto às suas composições. } \\
\hline \multicolumn{5}{|l|}{ Percebe que as vogais estão presentes em todas as sílabas. } \\
\hline \multicolumn{5}{|l|}{ Lê, ajustando a pauta sonora ao escrito. } \\
\hline \multicolumn{5}{|l|}{$\begin{array}{l}\text { Domina as correspondências entre letras ou grupos de letras e } \\
\text { seu valor sonoro, de modo a ler palavras e textos. }\end{array}$} \\
\hline $\begin{array}{l}\text { Domina as correspondências entre letras ou grupos de letras e } \\
\text { seu valor sonoro, de modo a escrever palavras e textos. }\end{array}$ & & & & \\
\hline
\end{tabular}

\section{Quadro 3 - Ficha sugerida pelo Pnaic e utilizada como instrumento de registro das avaliações feitas sobre as aprendizagens da turma}

\begin{tabular}{|c|c|c|c|}
\hline Conhecimento / Capacidade & Sim & Parcialmente & Não \\
\hline \multicolumn{4}{|l|}{ Escreve o próprio nome. } \\
\hline \multicolumn{4}{|l|}{ Reconhece as letras do alfabeto por seus nomes. } \\
\hline \multicolumn{4}{|l|}{ Diferencia letras de números e outros símbolos. } \\
\hline \multicolumn{4}{|l|}{ Utiliza letras na escrita da palavras. } \\
\hline \multicolumn{4}{|l|}{$\begin{array}{l}\text { Escreve palavras estabelecendo algumas correspondências } \\
\text { entre letras e seu valor sonoro, mesmo omitindo, mudando a } \\
\text { ordem ou trocando letras. }\end{array}$} \\
\hline \multicolumn{4}{|l|}{$\begin{array}{l}\text { Escreve palavras com diferentes estruturas silábicas, } \\
\text { atendendo a algumas convenções ortográficas. }\end{array}$} \\
\hline \multicolumn{4}{|l|}{ Lê palavras formadas por diferentes estruturas silábicas. } \\
\hline \multicolumn{4}{|l|}{ Lê textos de gêneros e temáticas familiares em voz alta. } \\
\hline \multicolumn{4}{|l|}{$\begin{array}{l}\text { Compreende textos de gêneros, temáticas e vocabulário } \\
\text { familiares. }\end{array}$} \\
\hline \multicolumn{4}{|l|}{$\begin{array}{l}\text { Produz textos escritos de gênero, temática e vocabulário } \\
\text { familiares. }\end{array}$} \\
\hline \multicolumn{4}{|l|}{$\begin{array}{l}\text { Participa de situações produzindo e compreendendo textos } \\
\text { orais de gêneros e temas familiares. }\end{array}$} \\
\hline $\begin{array}{l}\text { Obs. Em cada coluna deve-se indicar a quantidade de crianças que domina o cor } \\
\text { quantidade de crianças que domina parcialmente (Parcialmente) e a quantidade }\end{array}$ & $\begin{array}{c}\text { ciment } \\
\text { criança }\end{array}$ & $\begin{array}{l}\text { descrito (Sim), a } \\
\text { s que não domina }\end{array}$ & \\
\hline
\end{tabular}




\section{Caminho metodológico}

A abordagem qualitativa de pesquisa em educação (Lüdke; André, 1986; André, 2005) permitiu a construção de um mapeamento ancorado no método do paradigma indiciário (Ginzburg, 1991), que auxiliou a captação de indícios de que os professores alfabetizadores participantes da FC passaram a ressignificar o processo de avaliação a partir das mudanças de suas práticas pedagógicas sobre a alfabetização, alicerçando-as nos direitos de aprendizagem.

Conforme proposto por Ginzburg (1991), o método do paradigma indiciário focaliza os resíduos e os dados marginais considerados reveladores, em que se examinam os pormenores, ressaltando as características dos detalhes, a princípio secundários e aparentemente insignificantes.

O corpus foi composto por documentos do acervo do programa Pnaic na Unifap. Trata-se de instrumentos formativos e de diagnóstico, construídos e utilizados na FC: diário reflexivo (DR), momento interdisciplinar (MI) e relatórios descritivos de formação (RDF). O primeiro, DR, tinha por foco os alfabetizadores; o segundo, MI, os orientadores de estudos (OE) e alfabetizadores. O relatório, RDF, era de responsabilidade dos OE e coordenadores.

Considera-se a noção de DR, conforme André e Pontin (2010), configurada como ferramenta que revela reflexões e tomadas de consciência dos professores a respeito de suas próprias aprendizagens em contexto de formação continuada.

O MI configurou-se como proposta de indução aos orientadores de estudos e, na cadeia da FC, aos alfabetizadores, para incorporarem atividades que trabalhassem a alfabetização de modo interdisciplinar.

O RDF abarcava o registro de diversas informações sobre o trabalho desenvolvido pelos OE junto aos alfabetizadores e acompanhado pelos coordenadores.

Em síntese, trata-se de instrumentos de registros da FC (planejamentos, diagnósticos, relatos, sequências didáticas e materiais didáticos diversos, como jogos, brincadeiras, leituras deleite etc.) e de acompanhamento das práticas nas escolas pelos alfabetizadores.

Considerando o número de envolvidos - 1.227 alfabetizadores, 66 OE e 16 coordenadores locais -, abrangendo os 16 municípios do Estado do Amapá, os documentos referentes aos dois anos de FC, somavam um quantum significativo. De uma amostra aleatória, foram observados apenas fatos, a partir de indícios (Ginzburg, 1991), que revelavam mudanças/ressignificações do processo de avaliação, subjacentes às práticas/ações pedagógicas de alfabetização, alicerçadas pelos direitos de aprendizagem.

Desse prisma, a pesquisa qualitativa, com base nos princípios sócio-históricodiscursivos, força reconhecer que os dados construídos em uma relação entre sujeitos possibilitada pela linguagem somente podem ser interpretados dialogicamente (Bakhtin, 2003). 


\section{Perspectivas de avaliação subjacentes ao trabalho dos alfabetizadores no início da formação continuada}

O primeiro documento a ter descritos seus dados sobre o trabalho desenvolvido foi um diagnóstico realizado por meio de formulário aplicado aos participantes como forma de conhecer e avaliar suas visões e práticas de alfabetização, entre elas a avaliação. Serviu como pano de fundo para fomentar as reflexões iniciais da FC, em 2014, e ajudou a compreender o perfil de alfabetizadores que estavam se apresentando.

Entre as questões do formulário estavam as que procuravam saber do professor com quais materiais didáticos trabalhava para alfabetizar, com qual perspectiva de ensino de alfabetização acreditava atuar e como avaliava a aprendizagem das crianças. Neste texto, somente interessaram os dados referentes à última questão (Gráfico 1).

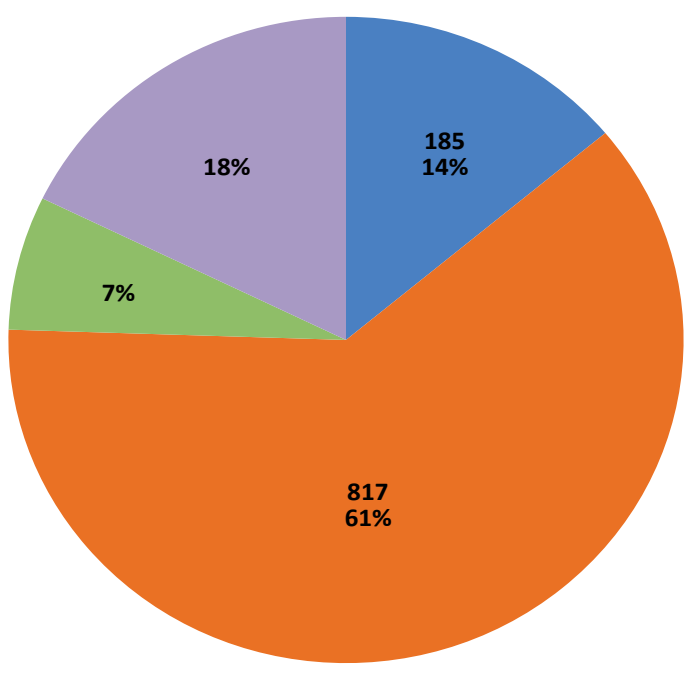

- Por observação dos avanços das crianças no desenvolvimento de atividades durante o bimestre.

Por acompanhamento com atividades e provas bimestrais e semestrais de avaliação

Por aplicação de prova e trabalhos em datas previamente agendadas com as crianças

- Por acompanhamento com fichas em que constam o que cada aluno precisa aprender sobre leitura, escrita e matemática

Gráfico 1 - Procedimentos de avaliação utilizados pelos alfabetizadores antes da formação continuada

Fonte: Elaboração própria, com base no acervo Pnaic/Unifap.

As respostas mostram que, no início da FC, o perfil dos alfabetizadores se apresentava com um percentual (61\%, 817 especificamente) mais elevado de docentes cujas práticas não permitiam ver a progressão do que se ensinava ao longo do ciclo. Os indícios disso restaram no fato de eles pautarem as avaliações em provas e atividades, com valor da nota ao final de um dado período, que se inscreviam no paradigma positivista/tradicional (Ferreira; Leal, 2010; Suassuna, 2007), homogeneizando os procedimentos, os sujeitos e seus tempos de aprender. 


\section{Indícios de ressignificação nas perspectivas de avaliação subjacentes aos discursos e práticas dos alfabetizadores no processo da formação continuada}

O Gráfico 2 foi construído com base em um trabalho de buscas dos indícios que vinham sendo percebidos no decorrer da FC e nos registros dos instrumentos formativos. Os elementos/fatos mapeados revelaram dois aspectos que se interrelacionam: o primeiro aspecto diz respeito à incorporação no fazer docente de um planejamento de ações/práticas didáticas alinhadas aos direitos de aprendizagem; o segundo se refere à incorporação no fazer docente da avaliação formativa alinhada aos direitos de aprendizagem.

No decorrer da FC foi notado que os alfabetizadores iam se apropriando de diversos saberes, incorporando-os tanto em seus discursos percebidos, sobretudo nos DR, quanto em suas práticas. Estas, embora descritas também no DR, eram acompanhadas pelos OE e coordenadores locais nas escolas e apresentadas nos RDF. Entre esses saberes, um dos princípios basilares do Pnaic diz respeito aos direitos de aprendizagem.

Com relação aos dois aspectos evidenciados, a ressignificação se revela por alguns indícios que seguem descritos, amparados pelos Gráficos 2 e 3 e pelas reflexões que deles resultarão.

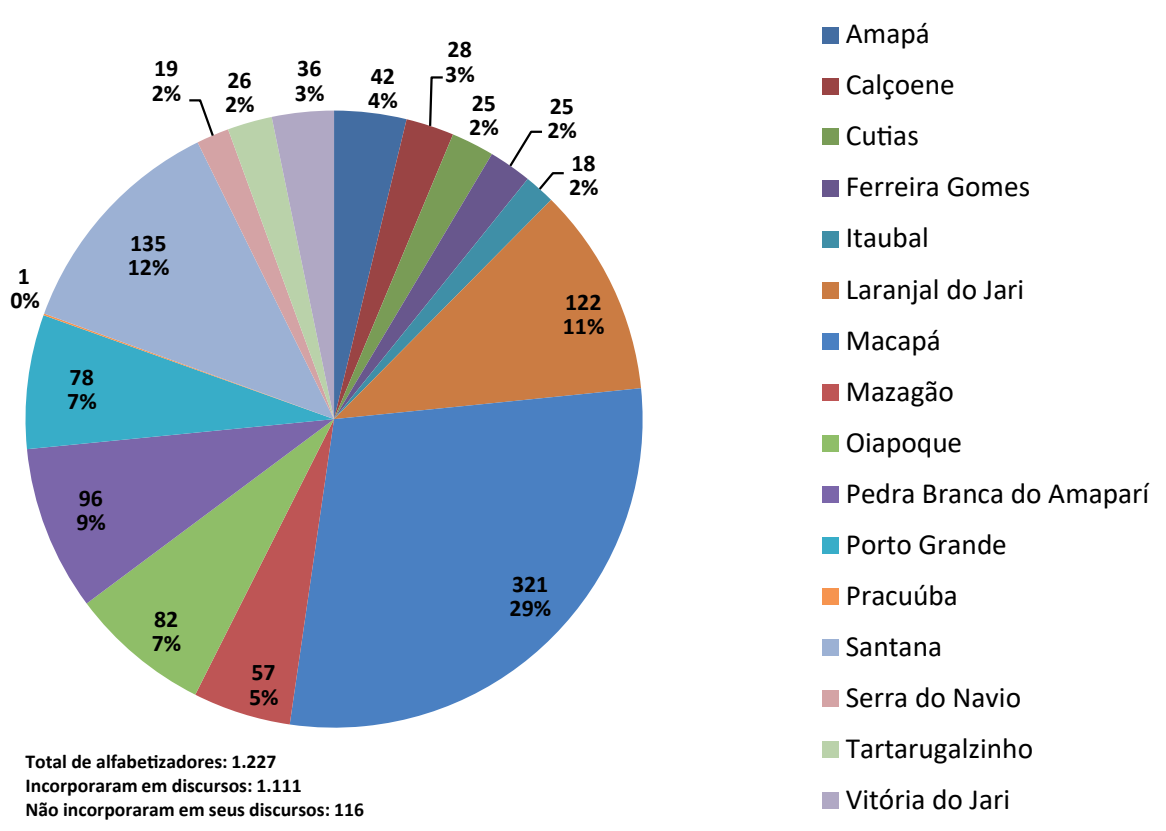

Gráfico 2 - Mapeamento dos alfabetizadores que incorporaram noções e conceitos dos Direitos de Aprendizagem em seus discursos profissionais - por município - Estado do Amapá

Fonte: Elaboração própria, com base no acervo do programa Pnaic/Unifap. 
Um indício significativo considerado inicialmente é o número de alfabetizadores que passaram a incorporar, em seus discursos profissionais, os direitos de aprendizagem. Do total de 1.227 alfabetizadores, 1.111 apresentavam em seus discursos essa apropriação, seja por meio dos registros no DR, seja por meio do registro nos RDF ou nos MI. Esse indício somado a trechos de DR revela a ressignificação de suas práticas didáticas e, subjacente a estas, a prática avaliativa, que vinha se percebendo no decorrer da FC, conforme excertos a seguir retirados dos acervos de DR do Pnaic/Unifap (2015):

[...] quanto à realização das atividades, superaram nossas expectativas quanto aos avanços percebidos ao avaliar os Direitos de Aprendizagem previstos, entre outros, na Leitura [...]. (Excerto - DR - Santana, AP - Grifo do autor).

[...]. Pelo tempo estimado da atividade, pude observar que os alunos adquiriram o hábito de ler textos e conseguiram entender e interpretar o que estavam lendo, relacionaram as ilustrações com o texto, e internalizaram de forma proveitosa os conhecimentos que adquiriram através do que leram e interpretaram. (Excerto - DR - Macapá, AP - Grifo do autor).

[...] Avaliamos o avanço dos alunos por meio dos Direitos de Aprendizagem e a partir da proposta da sequência de atividades planejadas utilizamos diversos recursos didáticos disponibilizados pelo MEC. (Excerto - DR - Vitória do Jari, AP - Grifo do autor).

Verifica-se que o princípio dos direitos de aprendizagem norteia todo o processo de ensino e aprendizagem dos conhecimentos que precisam ser construídos no ciclo da alfabetização, e se apresenta como recurso para acompanhamento das aprendizagens dos sujeitos, subsidiando os instrumentos de avaliação, conforme se pode ver nas sugestões das fichas supracitadas. O professor, ao tomar os direitos de aprendizagem, passa a investir em registros diários sobre as atividades realizadas pelas crianças, ora coletivamente, ora individualmente (Fetzner, 2013).

Por essa compreensão, com amparo na leitura de Bakhtin (2003), o sujeito se constitui na linguagem e pela linguagem, ou seja, por seu discurso nas múltiplas esferas da vida social. É esse discurso que reflete a visão de mundo e as crenças desse sujeito, que podem ser alteradas em um processo de (re)significações e (re) definições, e será no confronto e no conflito entre as várias identidades que o diálogo abre a possibilidade de reconstrução (Pereira; Sanchis; Moreira, 2010).

Nesse contexto, no início da FC os indícios apontavam para uma perspectiva de avaliação que se debruçava sobre provas e testes em períodos predeterminados, alinhada à dimensão do paradigma tradicional: uma avaliação que visa à classificação e que tem por base a capacidade de reprodução do aluno; um viés mimético, tal como explica Suassuna (2007). Os indícios captados, distintamente desse viés, revelam não somente o percentual significativo de alfabetizadores que incorporam os princípios de uma avaliação formativa, concebida como parte natural do processo de ensinar e aprender, mas que as mudanças nas práticas avaliativas alteraram as relações com a didática desses professores (Fernandes, 2013, p. 15).

No Gráfico 3, reúnem-se elementos que traduzem outros indícios de ações/ práticas didáticas dos professores alfabetizadores de que houve a incorporação das 
teorias e práticas que balizam o Pnaic, centralizadas em um planejamento alinhado às necessidades das crianças, ou seja, no direito que essas crianças têm de aprender. Isso é demonstrado, por exemplo, pelo número significativo de alfabetizadores (1.079) que passaram a construir práticas de sala de aula que refletem o trabalho planejado em uma progressão clara de "o que", "para quem" e "como" acompanhar e avaliar.

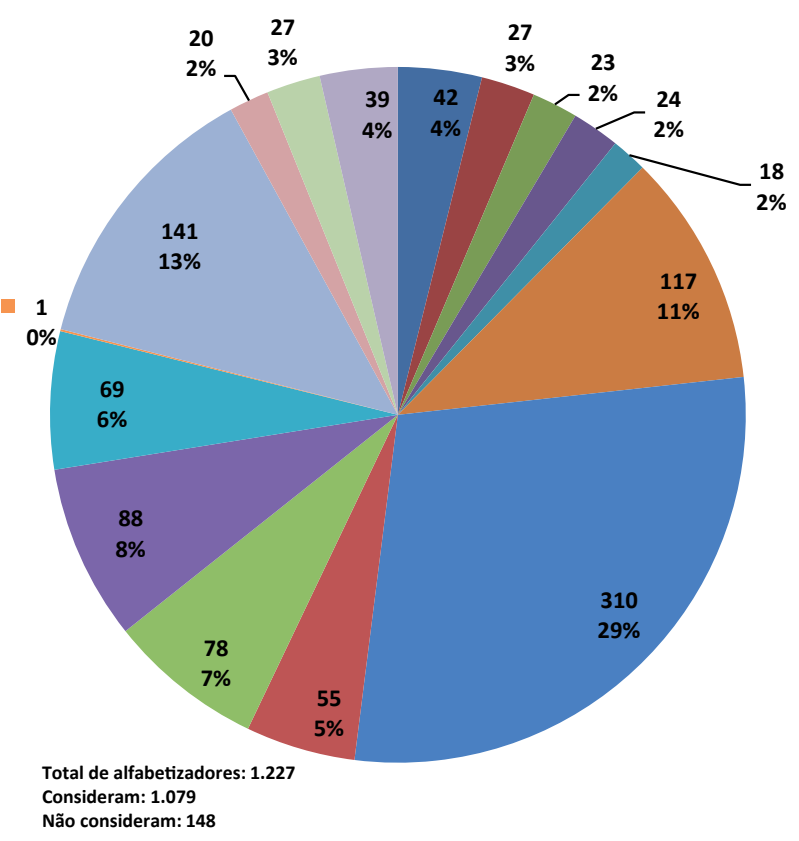

\author{
Amapá \\ - Calçoene \\ - Cutias \\ - Ferreira Gomes \\ - Itaubal \\ - Laranjal do Jari \\ - Macapá \\ - Mazagão \\ - Oiapoque \\ - Pedra Branca do Amaparí \\ - Porto Grande \\ Pracuúba \\ - Santana \\ - Serra do Navio \\ Tartarugalzinho \\ Vitória do Jari
}

\title{
Gráfico 3 - Índices de alfabetizadores cujas ações didáticas incorporaram: diagnóstico, plano de atividades, avaliação e replanejamento - por município - Estado do Amapá
}

Fonte: Elaboração própria, com base no acervo do programa Pnaic/Unifap.

Os direitos de aprendizagem tornaram-se orientadores dos alfabetizadores para iluminar quais saberes encontravam-se consolidados e quais precisariam ainda ser ensinados ou retomados, pensando-se em um planejamento cuja progressão pudesse ser garantida.

Sustentam-se essas compreensões principalmente com base nos RDF que descreviam o acompanhamento feito nas escolas pelos OE e coordenadores locais. Os indícios apontados numericamente podem ser corroborados por excertos de RDF e DR, que demonstram a integração entre o processo de ensino-aprendizagem e o de avaliação dessa aprendizagem. São apresentados a seguir os excertos dos relatórios da FC de três municípios, bem como dois excertos de DR sobre atividades planejadas e desenvolvidas (grifos nossos).

Cerca de 85\% dos professores alfabetizadores aplicaram as metodologias discutidas e sugeridas nos encontros de formação, e usaram os Direitos de aprendizagem como suporte [...] em suas turmas e socializavam estes resultados no retorno dos encontros de formação [...]. (Excerto - RDF - Santana, AP). 
[...], seguindo o cronograma junto aos Professores Alfabetizadores e acompanhamos as escolas permitindo perceber que os alfabetizadores se envolveram com as propostas do PNAIC e passaram a usar os materiais e as estratégias, apoiando-se nos Direitos de Aprendizagem ensinados na Formação em sala. (Excerto - RDF - Macapá, AP).

A formação foi bastante produtiva [...]. Agora conseguimos ver eles com aulas mais dinâmicas e, o melhor, a gente percebe que eles têm mais clareza "do quê" e do "para que e quem" estão ensinando, não ficando presos somente em conteúdos desarticulados das necessidades dos alunos, mas nas capacidades dos Direitos [...]. (Excerto - RDF - Laranjal do Jari, AP).

Essa proposta de atividades ora planejada para o terceiro ano do ensino fundamental busca agregar conhecimentos construídos dos alunos e já sistematizados a outros previstos aqui, [...] dessa maneira uma prática articulada a um currículo vivo, no que concernem às experiências de cada aluno. Destacase ainda que o processo de alfabetização é único em cada criança e este deve ser trabalhado de uma forma estimulante, incentivadora e lúdica [...] tendo claro pelo diagnóstico avaliativo o que os alunos precisam desenvolver quanto aos Direitos de Aprendizagem. [...], a referida abordagem torna-se interdisciplinar na medida em que permite um leque de conhecimentos a serem abordados nas diversas disciplinas, tais como: Português, Matemática, Ciências, Artes e Ensino Religioso. (Excerto - DR).

O Planejamento que construímos tratou de uma sequência de atividades elaboradas para trabalhar com as crianças do primeiro ano do Ensino Fundamental. Neste planejamento priorizamos o Eixo Análise linguística - Apropriação do Sistema de Escrita porque nele está o número maior de capacidades, a partir dos Direitos de aprendizagem verificados, que os alunos da turma precisam consolidar para avançar no processo de alfabetização, sem perder de vista o letramento. Mas outros Eixos estão previstos também. (Excerto - DR).

Por meio dos RDF, verificam-se elementos de ações planejadas coletivamente pelos diferentes sujeitos que compõem a FC. Nessa direção, pode-se dizer que se trata de mais uma evidência de que a FC provocou a ressignificação no modo de agir didaticamente do professor, incluindo-se aí a forma de avaliar, uma vez que figura nos planejamentos a previsão da verificação (avaliando-se, portanto, a progressão dos saberes) dos direitos de aprendizagens desenvolvidos ou não pelos alunos. Nesse sentido, reflete o que Leal (2012, p. 19) também explicita nos cadernos da FC: "o planejamento da ação pedagógica e a organização das informações sobre as crianças e dos materiais de uso são os pilares básicos para que as intenções docentes sejam concretizadas e todas as crianças aprendam o que lhes é de direito".

Como consequência dessa breve exposição, verificam-se marcas importantes que sintetizam os dois aspectos revelados pelos indícios captados nos instrumentos formativos que compuseram o corpus deste texto: que houve, de maneira vinculada, a incorporação no fazer docente de um planejamento de ações/práticas didáticas alinhadas aos direitos de aprendizagem e a incorporação no fazer docente da avaliação formativa alinhada aos direitos de aprendizagem.

A FC não influenciou somente o processo de avaliar, mas o de planejar. Houve ressignificação no pensar e no agir pedagógicos, demonstrada pela apropriação da grande premissa do Pnaic, que são os direitos de aprendizagem. Incorporou-se um modo de progressão do planejamento das ações didáticas, que pode ser mais bem compreendido com o auxílio da Figura 1. 


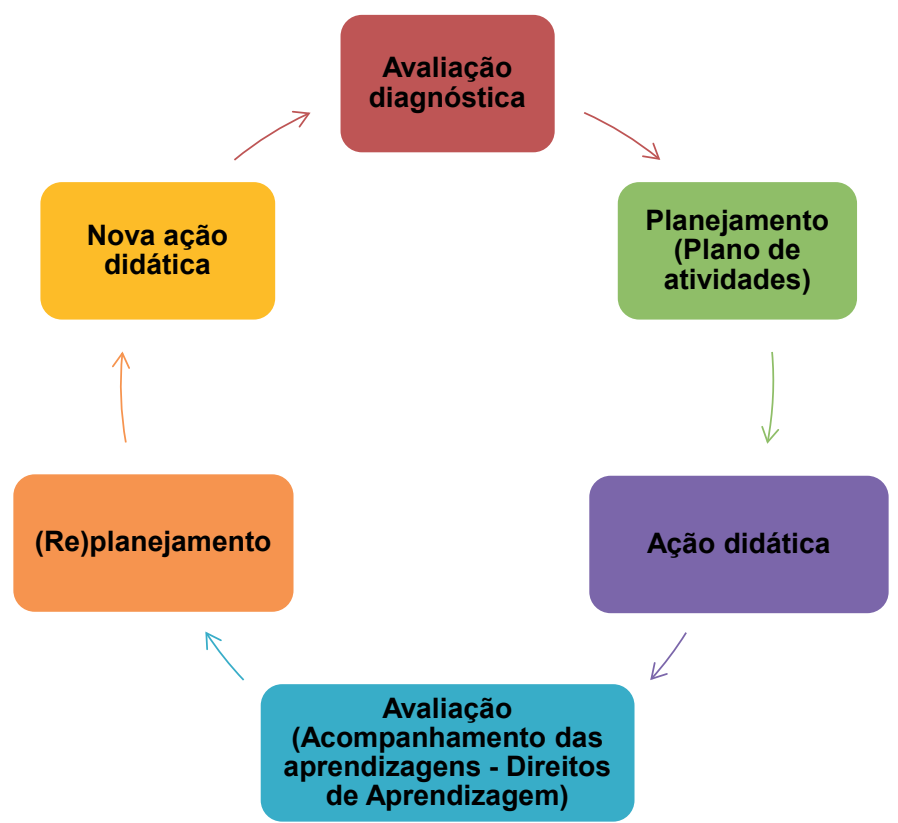

Figura 1 - Progressão do planejamento e das ações didáticas

Fonte: Elaboração própria.

A perspectiva de avaliação formativa foi evidenciada na cadeia multiplicadora de formação, o que significa dizer que, como uma das premissas do Pnaic era que houvesse acompanhamento nas escolas, pelos atores da FC, foi possível ainda estabelecer "o momento de fazer juntos". A prática avaliativa se vinculou ao objetivo de qualificar o processo de ensino e aprendizagem, considerando a perspectiva de que "uma ação didática consistente pressupõe necessariamente uma atividade diagnóstica para que o professor possa conhecer melhor os estudantes e reorganizar seu planejamento em função de suas necessidades" (Brasil. MEC. SEB, 2012b, p. 8).

Não se pode desconsiderar que os indícios não atestam ressignificação incorporada por todos os 1.227 alfabetizadores, e isso pode ser explicado pela "contradição entre o discurso e a prática de alguns educadores a respeito da ação classificatória e autoritária exercida pela maioria", já que "isso é um reflexo de suas histórias de vida como professor e aluno" (Hoffmann, 2003, p. 12).

\section{Considerações finais}

Os dados apresentados traduzem indícios de alteração do fazer pedagógico dos alfabetizadores que, embora não na sua totalidade, passaram a "reinventar suas pedagogias"; na interpretação de Morais (2012), tanto em relação ao planejamento de suas ações didáticas, como em relação ao modo de avaliar na perspectiva diagnóstica e formativa com base nos princípios dos direitos de aprendizagem. 


\section{Referências bibliográficas}

ANDRÉ, M. E. D. A. Estudo de caso em pesquisa e avaliação educacional. Brasília: Liber Livro, 2005.

ANDRÉ, M. E. D. A.; PONTIN, M. M. D. O diário reflexivo, avaliação e investigação didática. Revista Meta: Avaliação, Rio de Janeiro, v. 2, n. 4, p. 13-30, jan./abr. 2010.

BAKHTIN, M. Estética da criação verbal. Tradução de Paulo Bezerra. 4. ed. São Paulo: Martins Fontes, 2003.

BRAIT, B. A natureza dialógica da linguagem: formas e graus de representação dessa dimensão cognitiva. In: FARACO, C. F; TEZZA, C.; CASTRO, G. (Orgs.). Diálogos com Bakhtin. 3. ed. Curitiba: Editora da UFPR, 2001. p. 69-92.

BRASIL. Ministério da Educação (MEC). Portaria no 867, de 4 de julho de 2012. Institui o Pacto Nacional pela Alfabetização na Idade Certa e as ações do Pacto e define suas diretrizes gerais. Diário Oficial da União, Brasília, DF, 5 de jul. 2012. Disponível em: <http://portal.mec.gov.br/index.php?option=com docman\&view = download\&alias $=11125-05072012$-portaria-867\&category_ slug =junho-2012-pdf\&Itemid=30192> . Acesso em: 16 out. 2020 .

BRASIL. Ministério da Educação (MEC). Secretaria de Educação Básica (SEB). Elementos conceituais e metodológicos para definição dos direitos de aprendizagem e desenvolvimento do ciclo de alfabetização $\left(1^{\circ}, 2^{\circ}\right.$ e $3^{\circ}$ anos) do ensino fundamental. Brasília: MEC, 2012a.

BRASIL. Ministério da Educação (MEC). Secretaria de Educação Básica (SEB). Pacto Nacional pela Alfabetização na Idade Certa: avaliação no ciclo de alfabetização: reflexões e sugestões. Brasília: MEC, 2012b.

BRASIL. Ministério da Educação (MEC). Secretaria de Educação Básica (SEB). Pacto Nacional pela Alfabetização na Idade Certa: currículo na alfabetização: concepções e princípios - ano 01, unidade 01. Brasília: MEC, 2012c. Disponível em: < https:// wp.ufpel.edu.br/obeducpacto/files/2019/08/Unidade-1.pdf>. Acesso em: 16 out. 2020.

BRASIL. Ministério da Educação (MEC). Secretaria de Educação Básica (SEB). Pacto Nacional pela Alfabetização na Idade Certa: formação do professor alfabetizador: caderno de apresentação. Brasília: MEC, 2012d.

FERNANDES, C. O. Avaliação da aprendizagem não é medida: reprovação não garante qualidade. Salto para o Futuro, [S. 1.], v. 23, n. 8, p. 10-19, maio 2013.

FERREIRA, A. T. B.; LEAL, T. F. Formação continuada de professores: enfim, o que pensam e sugerem os docentes? In: FERREIRA, A. T. B.; CRUZ, S. P. Formação continuada de professores: reflexões sobre a prática. Recife: Editora Universitária da UFPE, 2010. p. 69-86. 
FERREIRA, A. T. B.; ROSA, E. C. S.; TELES, R. Atividades lúdicas: hora de aprender, hora de avaliar? In: BRASIL. Ministério da Educação (MEC). Secretaria de Educação Básica (SEB). Pacto Nacional pela Alfabetização na Idade Certa: vamos brincar de reinventar histórias - ano 03, unidade 04. Brasília: MEC, 2012. p. 28-31.

FETZNER, A. R. Quando a avaliação precisa dar certo: os desafios da não reprovação. Salto para o Futuro, [S. 1.], v. 23, n. 8, p. 20-23, maio 2013.

GINZBURG, C. Sinais: raízes de um paradigma indiciário. In: GINZBURG, C. Mitos, emblemas, sinais. São Paulo: Companhia das Letras,1991.

HOFFMANN, J. M. L. Avaliação: mito e desafio: uma perspectiva construtivista. Porto Alegre: Mediação, 2003.

LEAL, T. F. Avaliação e organização do trabalho docente: a importância dos registros. In: BRASIL. Ministério da Educação (MEC). Secretaria de Educação Básica (SEB). Pacto nacional pela alfabetização na idade certa: organização do trabalho docente para promoção da aprendizagem - ano 01, unidade 08. Brasília, 2012. p. 15-19.

LEAL, T. F.; AlBUQUERQUE, E. B. C.; MORAIS, A. G. (Orgs.). Alfabetizar letrando na EJA: fundamentos teóricos e propostas didáticas. Belo Horizonte: Autêntica, 2010. (Coleção Estudos em EJA).

LUCKESI, C. C. Educação, ludicidade e prevenção das neuroses futuras: uma proposta pedagógica a partir da biossíntese. In: LUCKESI, C. C. Ludopedagogia: educação e ludicidade. Salvador: UFBA, Faced, PPGE, 2000. P. 9-42.

LÜDKE, M.; ANDRÉ, M. E. D. A.; Pesquisa em educação: abordagens qualitativas. São Paulo: EPU, 1986. (Temas Básicos em Educação e Ensino).

MORAIS, A. G. Políticas de avaliação da alfabetização: discutindo a Provinha Brasil. Revista Brasileira de Educação, Rio de Janeiro, v. 17, n. 51, p. 551-571, set./dez. 2012.

PEREIRA, G. B.; SANCHIS, I. P.; MOREIRA, L. R. Sujeito, sociedade e discurso. Arquivos Brasileiros de Psicologia, Rio de Janeiro, v. 62, n. 2, p. 2-13, 2010.

PERRENOUD, Ph. Construir as competências desde a escola. Porto Alegre: Artmed, 1999.

SAUL, A. M. Avaliação emancipatória: desafios à teoria e à prática de avaliação e reformulação de currículo. 3. ed. São Paulo: Cortez, 1995.

SUASSUNA, L. Instrumentos de avaliação em língua portuguesa: limites e possibilidades. In: MARCUSCHI, B.; SUASSUNA, L. (Org.). Avaliação em Língua Portuguesa: contribuições para a prática pedagógica. Belo Horizonte: Autêntica, 2007. P. 111-126. 
Adelma das Neves Nunes Barros-Mendes, doutora em Linguística Aplicada e Estudos da Linguagem pela Pontifícia Universidade Católica de São Paulo (PUC-SP), com estágio de doutorado na Universidade de Genebra, Suíça, é professora associada 1 da Universidade Federal do Amapá (Unifap), da qual foi vice-reitora. Coordena o Laboratório Interdisciplinar de Pesquisa e Inovação Tecnológica (Latec/Unifap).

adelma@unifap.br

Adriana Carvalho Souza Castro, especialista em Metodologia do Ensino de Língua Portuguesa e Literatura pelo Instituto de Ensino Superior do Amapá (Iesap), professora de Língua Portuguesa da rede pública estadual e professora substituta no Departamento de Letras e Artes da Universidade Federal do Amapá (Unifap). adriana.castro@ueap.edu.br

Heloane Baia Nogueira, mestra em Desenvolvimento Regional pela Universidade Federal do Amapá (Unifap) e especialista em Metodologia do Ensino de Língua Portuguesa e Literatura pelo Instituto de Ensino Superior do Amapá (Iesap), integra o Núcleo de Estudos e Pesquisa em Linguística Aplicada (Nepla) e participa como professora de educação a distância na área de Linguagem pela Universidade Aberta do Brasil (UAB/Unifap).

helobaia84@gmail.com

Rosivaldo Gomes, doutor em Linguística Aplicada pela Universidade Estadual de Campinas (Unicamp) na área de Linguagens e Educação Linguística, é professor adjunto II de Língua Portuguesa e Didática das Línguas no Departamento de Letras e Artes da Universidade Federal do Amapá (Unifap) e docente permanente do Programa de Pós-Graduação em Letras (PPGLET/Unifap).

rosivaldounifap12@gmail.com

Recebido em 31 de março de 2020

Aprovado em 8 de maio de 2020 